\title{
Research and Discovery Science and the Future of Dental Education and Practice
}

\author{
Peter J. Polverini, DDS, DMSc; Paul H. Krebsbach, DDS, PhD \\ Abstract: Dental graduates of 2040 will face new and complex challenges. If they are to meet these challenges, dental schools \\ must develop a research and discovery mission that will equip graduates with the new knowledge required to function in a \\ modern health care environment. The dental practitioner of 2040 will place greater emphasis on risk assessment, disease preven- \\ tion, and health maintenance; and the emerging discipline of precision medicine and systems biology will revolutionize disease \\ diagnosis and reveal new targeted therapies. The dental graduate of 2040 will be expected to function effectively in a collabora- \\ tive, learning health care system and to understand the impact of health care policy on local, national, and global communities. \\ Emerging scientific fields such as big data analytics, stem cell biology, tissue engineering, and advanced biomimetics will impact \\ dental practice. Despite all the warning signs indicating how the changing scientific and heath care landscape will dramatically al- \\ ter dental education and dental practice, dental schools have yet to reconsider their research and educational priorities and clinical \\ practice objectives. Until dental schools and the practicing community come to grips with these challenges, this persistent attitude \\ of complacency will likely be at the dental profession's peril. This article was written as part of the project "Advancing Dental \\ Education in the $21^{\text {st }}$ Century."
}

\begin{abstract}
Dr. Polverini is Jonathan Taft Distinguished University Professor of Dentistry, Department of Periodontics and Oral Medicine, University of Michigan School of Dentistry and Professor, Department of Pathology, University of Michigan Medical School; and Dr. Krebsbach is Dean and Professor, University of California, Los Angeles, School of Dentistry. Direct correspondence to Dr. Peter J. Polverini, Department of Periodontics and Oral Medicine, University of Michigan School of Dentistry, 1011 North University Ave., Room G020A, Ann Arbor, MI 48109-1078; 734-764-1543; neovas@umich.edu.
\end{abstract}

Keywords: research, discovery science, dental education, innovation, personalized health care, precision medicine, health policy

Submitted for publication 2/5/17; accepted 3/9/17

doi: 10.21815/JDE.017.040

$\mathrm{T}$ This article was written as part of the project "Advancing Dental Education in the $21^{\text {st }}$ Century." Since the Institute of Medicine report on the future of dental education was published in 1995 , its recommendation to expand the research capacity of dental schools has remained largely unfulfilled. ${ }^{1}$ Both the National Institutes of Health (NIH) and National Institute of Dental and Craniofacial Research (NIDCR) have expanded training programs for future faculty and provided new research opportunities for dental schools. Yet, with a few exceptions, most dental schools have failed to maximize these opportunities. ${ }^{2}$ As a result, most dental schools have not adequately developed and supported the next generation of dentist/clinician scientists capable of competing for extramural research funding.

A number of factors contribute to this lack of progress in expanding the research capacity of dental schools. First, many dental school faculty members are ill prepared to succeed in an increasingly competitive research environment. This deficiency is due not only to a lack of well-trained faculty members, but also to the inability of most dental schools to provide adequate resources needed to hire and support clinician-scientists. Another deficiency that has contributed to the limited success in acquiring extramural research support is that, with some exceptions, ${ }^{3,4}$ schools provide inadequate mentoring of promising junior faculty. Formal mentoring programs that better prepare faculty members to compete for extramural research dollars can enhance the success rate of new investigators. For example, the University of Michigan Medical School's R01 Boot Camp is a rigorous mentored research program for junior faculty members in which they are prepared for the process of grantsmanship and peer review. For those who participate in this program, the success rate for individual awards approaches $50 \%$ significantly higher than the average success rate of less than $20 \%$ for all investigators at that school. A final reason is our perception that a number of dental schools have either delayed implementation of or reduced investment in their schools' research and discovery mission.

A steady decline in the number of dental school faculty members successfully competing for research funds was a disturbing trend reported in 2011. ${ }^{2}$ That study found that, between 2005 and 2009, U.S. dental schools received fewer than $50 \%$ of NIDCR awards; and although 56 dental schools received NIH grants, the majority of grant support was awarded to only 12 of them. This imbalance suggests that only 
some schools were placing an emphasis on research and that the result was an increasingly tiered level of education among schools. A recent follow-up study by Ferland et al. reported that, over a ten-year period (2005-14), the NIH provided approximately $\$ 2.2$ billion dollars (from 20 of its institutes) to 56 dental schools, with the NIDCR being the largest supporter ( $\$ 1.5$ billion) of projects at those institutions. ${ }^{5}$ That study reported that the NIDCR provided $92 \%$ of NIH support for research training and career development. Despite this 10\% net decrease in extramural research dollars by NIH and NIDCR and a $30 \%$ total decrease when adjusted for inflation, there has not been the projected steep decline in research support to dental schools. Despite NIH's and NIDCR's continued investment in research training and investigator-initiated research, the number of dental schools competing for a reduced pool of research dollars has for all practical purposes remained the same. With limited growth in training programs, it is unlikely there will be sufficient numbers of dentistscientists able to contribute to the discovery science that will transform future dental practice. While the precipitous drop in funding to dental schools has not materialized as once predicted, it is becoming increasingly difficult for both new and established dental schools to build and sustain research and training programs.

If more rapid progress is to be made in expanding the research capacity of dental schools and increasing opportunities for training of dentistscientists, more dental schools need to develop sustainable research and discovery missions. The continued uncertainty in research funding and research training has accelerated the risk of the dental profession falling further behind its health science peers. This risk jeopardizes dentistry's ability to embrace new areas of research, such as personalized medicine, that will propel our profession into the future ${ }^{6-8}$ By turning a blind eye to this unsettling trend, we run the risk of losing our identity as a science-driven health profession. The solutions are obvious. Training programs for future faculty need to be more rigorous, schools need to do a better job of mentoring their faculty members, and dental schools must make research and discovery a core value. Dental schools must find ways to increase the number of research-oriented faculty members and to provide them with facilities, equipment, mentoring, and an intellectual and collaborative environment where they can thrive and mentor their students in conducting research..$^{910}$
Only when dental students come to appreciate how research adds value to their education will they truly understand how research translates into better patient care. It is imperative that the drive for innovation and creativity serves as a catalyst for initiating new models of dental education. Indeed, generating and analyzing the evidence that results from exploring new models of education aimed at alleviating the burden of inadequate care in underserved communities, advancing oral health through innovative policy initiatives, or exploring how interprofessional practice can change the practice environment are as important as the science conducted by the bench researcher or clinical investigator. It is essential, and should be self-evident, that dental schools need to determine where they can best contribute not only to the research mission of their own university, but also to the advancement of the dental profession.

If dentistry is to remain a scientifically based profession and a leader in oral health care, dental schools need to consider whether integration with the other health professions schools may provide for a more sustainable future. Collaboration and sharing of academic resources among dental schools and the other health professions offer ways to invest in new scientific and patient care initiatives. Since many of the newer dental schools may lack the resources to develop a competitive research environment on their own, it should be possible to develop partnerships with more established research-intensive institutions where collaborative research and robust faculty training and mentoring programs already exist. Intra- and inter-institutional collaborations provide unique opportunities to identify and expand challenging research questions that address total health. Our challenge is to break down existing barriers and work on approaches that encourage creative and productive interactions. Examples of forward thinking interdisciplinary collaborations involving medicine-engineering-dentistry are the Wyss Institute for Biologically Inspired Engineering at Harvard University and the Biointerfaces Institute at the University of Michigan.

\section{Research as Essential to Dental Education and Practice}

Research innovation and scholarship have long been core values of dentistry. ${ }^{11-13}$ Scientific 
advances inform dental practice by paving the way for evidence-based decision making. ${ }^{14}$ Participation in research also directly impacts a dental student's educational experience..$^{10}$ At a minimum, research engages a student's intellectual curiosity and provides an outlet for creativity. Most importantly, it deepens a student's understanding and appreciation for the profession of dentistry and produces a practitioner better able to critically assess and apply new knowledge to dental practice.

As health care reform continues to evolve, the rapidly changing landscape will have a major impact on the practice of dentistry. Dentistry will need to take a more prospective approach to health care..$^{15,16}$ As new technologies evolve to facilitate diagnosis, dental schools will be expected to provide students with the most up-to-date knowledge and skills needed to focus their attention on disease risk, predict disease onset with accuracy and reliability, and intervene early to halt disease progression. ${ }^{17} \mathrm{By}$ integrating research and discovery into dental school curricula and by providing students with opportunities to directly participate in research, dental schools will prepare practitioners who will remain relevant and up-to-date in their knowledge and be better prepared to meet the challenges of the evolving health care environment.

With expanding curricula and continued financial constraints, Emrick and Gullard found that research opportunities for predoctoral dental students were becoming increasingly limited and were in danger of becoming a mere luxury at many schools. ${ }^{10}$ This trend threatens the long-held view that research and scholarship have inherent value in dental education and are integral to advancing dental practice. ${ }^{13}$ Moreover, in our experience, students who are given the opportunity to engage in a meaningful research experience are likely to have greater analytical skills and a greater appreciation for the role of scientific evidence in dental practice. A survey conducted by the American Association for Dental Research (AADR) National Student Research Group, designed to evaluate dental students' attitudes about research and scholarship and the barriers they face in accessing scholarly opportunities, identified several concerns. ${ }^{10}$ That study found a major obstacle to research participation was the lack of sufficient time in the curriculum. Despite an increased emphasis on evidence-based practice, students reported believing they were ill prepared in disciplines such as biostatistics and research methodology and were unprepared and/or lacked skills in critical thinking to evaluate and assess the value of the science that underpins decision making in their profession. The expectation for research conducted by students and faculty is outlined in Standard 6 of the Commission on Dental Accreditation (CODA) standards: "Dental education programs must provide opportunities, encourage, and support student participation in research and other scholarly activities mentored by faculty." ${ }^{18}$ Unfortunately, the breadth and quality of research experiences are not stipulated in the standard, nor are specific outcome measures defined. As resources shrink, leaders of dental schools must make difficult choices and manage competing interests. Infrastructure availability and high costs of maintaining contemporary research space can be prohibitive for schools that wish to develop new or expand existing research programs. As we migrate toward a more collaborative care environment, dental schools must capitalize on opportunities to reduce costs and maximize resources while improving the health of their patients. A similar collaborative approach is long overdue in the research community.

In light of the rapidly changing science and health care environment, dental education needs to be constantly adaptive. Perhaps a greater emphasis on collaborative, interdisciplinary learning may prompt dental schools to take a more progressive approach to health science education and practice. Just as experiential learning in community-based settings enhances a student's understanding and appreciation of the environmental and psychosocial experiences and social determinants of oral heath, one could make a similar argument that participation in research and scholarship by students is a valuable experiential learning opportunity.

The question at hand is not whether research and discovery are important to the future of the profession, but, rather, will dental schools be the place where the new knowledge is created? ${ }^{11,19}$ If dental schools are unwilling or unable to meet this responsibility, the profession they serve runs the risk of reverting to its apprentice-based origins and mortgaging its future to other health care disciplines that may not have the best interests of the dental profession in mind. ${ }^{20}$ A revisionist stance and the de facto policies that support this alternative future represent the biggest threat to dentistry as a profession. If we believe research and discovery are integral to the culture of dental education and the dental profession, it is imperative that all dental schools embrace research as a core value in a meaningful and tangible way. Abraham Flexner-who, like William Gies, advocated for the integration of 
medical and dental schools within the university environment - was of the opinion that research and teaching should be inseparable because the approach of the investigator and the clinician-teacher should be the same. ${ }^{13,21}$ Indeed, dental students who are not given a research experience are not likely to gain an explicit appreciation of emerging clinical evidence, developing technologies, and promising therapies that will advance the practice of dentistry.

\section{Personalized Oral Health Care and Precision Medicine}

As health care reform evolves, the health care system will shift its focus from disease management to disease prevention and health promotion. ${ }^{22-25}$ This system of care encourages interprofessional education and high-value collaborative care ${ }^{26-31} \mathrm{By}$ embracing this forward-thinking model of care, the dental profession could, and should, focus more on the management of oral health, accelerate the search for reliable biomarkers of risk assessment, and develop innovative diagnostic and interventional strategies designed to minimize disease progression. ${ }^{15,24}$ For many communities, access to care continues to be limited; and often when care is delivered, it is sporadic, uncoordinated, and fragmented..$^{26,29-31}$ The emphasis on oral hygiene education and the use of fluoride and dental sealants notwithstanding, our current system of dental care largely focuses on restorative care and chronic disease management. ${ }^{16,24,25}$ Although the current reductionist approach to dental practice has proven helpful in managing infectious diseases such as dental caries, it has been far less effective in managing more complex chronic diseases such as periodontal disease..$^{32}$ This limitation is due in part to an oversimplification of the disease process and tendency to discount the impact of genetics, culture, lifestyle choices, and environmental influences on health. As a consequence, optimal health is often viewed as the absence of disease rather than the result of a personalized plan that focuses on health maintenance. ${ }^{24}$

Humans' genetic makeup, environment and lifestyle choices, and the availability of care are factors that determine risk for disease; and what is missing in today's health care environment and educational systems are personalized plans for disease prevention and health promotion-plans that focus more on risk assessment and early intervention than on treatment. ${ }^{16,22-26,29,31,33-35}$ It is essential that dental schools prepare graduates to be successful providers in this new health care environment.

Providing patients with the right care at the right time that results in a measurable improvement in health outcomes at a lower cost will define personalized oral health care. ${ }^{24}$ Achieving this outcome will require a very different approach to care, in which providers are incentivized and reimbursed for preventing disease and helping patients develop personal plans for achieving optimal oral health. In such a system, oral health care professionals would be managing care delivered by an increasingly diverse workforce, and workforce innovations will focus more on disease prevention. ${ }^{36-40}$ Such examples exist in the modern practice of medicine with the expanded use of physician assistants and nurse practitioners. Although mid-level dental providers are being trained in Alaska and Minnesota, and the dental nurse model is in place in New Zealand, the dental profession in the U.S. seems to have been generally resistant to exploring similar alternative workforce models. Oral health care professionals would also be expected to participate in promoting health literacy and partnership with patients in the provision of their care. ${ }^{27,41}$ Oral health care professionals would also need to have a deeper knowledge of the complex interplay among factors that both determine health and lead to chronic disease. To be successful in this new health care environment, oral health care professionals would need to be conversant with the emerging sciences of genomic medicine, bio- and health informatics, and health policy and to be knowledgeable about the power and limitation of the emerging "omics" technologies. ${ }^{42,43}$ This will require greater exposure to general medicine in dental curricula. ${ }^{17,44-48}$ Contrary to the trends that will define future health care, the current trajectory of dental education, from our perspective, continues its primary focus on restorative care and a practice environment that is detached and isolated from the other health professions.

Collaborative care teams are expected to be an important feature of the personalized health care environment, and dentists will be expected to embrace their health professions colleagues in settings that are both challenging and exciting. ${ }^{18,31,49-56}$ To successfully train future members of a health care team, health professions schools will need to implement interprofessional competencies that embrace all 
health professions and that are driven by individual patient needs and communities of interest. These competencies will require continuous assessment to fine-tune and shape educational and practice setting outcomes. Ongoing evaluation of existing knowledge domains and competencies will require the development of a progressive educational agenda that strengthens scholarship and promote innovation. Health professions schools and accrediting agencies will need to embrace common standards that support interprofessional education and new models of collaborative care. These core competencies will inform credentialing bodies in defining appropriate content to develop credentialing standards for collaborative practice. It is becoming increasingly clear that the siloed approach to health professions education and practice will have a diminished role in the future. ${ }^{57}$

In the future, oral health professionals will use genomic data to assess risk to determine how best to help their patients make informed decisions about their care. While there are a number of single gene disorders that affect the orofacial structures, as genomic medicine continues to evolve, a more complex genetic basis for the most common dental diseases will no doubt be revealed. ${ }^{58-63}$ As for all health-related disciplines, educating oral health professionals about general medicine, genetics, and genomics will be essential for the informed clinical practitioner. Although medical school curricula are placing increased emphasis on the genetics basis of disease, studies in the United States and Europe have found dental professionals to be deficient in their knowledge of genetics and genomic medicine when compared to other health care professionals. ${ }^{64-70}$ While most dentists may believe that genomic medicine is peripheral and beyond their scope of practice, the ability to understand the power and limitations of genetic testing and the importance of individual genetic polymorphisms will in the future be an important part of the oral health professional's tool box. ${ }^{63,66,71}$ Future dental practitioners will only be viewed as valued partners in a personalized health care environment when dental education places a greater emphasis on evidence-based disease prevention risk assessment and personalized care.

Health policy is another knowledge domain that will be necessary for dental practitioners to effectively navigate the emerging personalized oral health care environment. A number of medical schools have developed programs to educate physicians about the impact of health care systems and the economics of health care on health policy. ${ }^{72-74}$ The need for future dentists to have an understanding of the values and importance of comparative and cost-effectiveness research and evidence-based practice will require that dental schools develop instruction in this domain. If personalized oral health care is to have a meaningful impact on the oral health of patients, dental schools must embrace these new educational initiatives.

William Gies and Abraham Flexner had a profound impact on the education of dentists and physicians, respectively. ${ }^{13,21,75}$ Their influence on the standardization of curricula, emphasis on scientific rigor, and insistence on academic integrity formedand continues to form - the cornerstone of modern health professions curricula. If dental students are expected to compete successfully in the coming health care environment and be productive members of an integrated health care team, several important elements in curriculum development must be taken into consideration..$^{19,76}$ The emerging prospective health care environment will provide enormous opportunities for innovation. The exploration of new academic partnerships with the other health professions will enable future dental practitioners to deliver the highest quality, patient-centered oral health care to an increasingly diverse patient population. While each of the professions will have its discipline-specific competencies and coursework, there will also be a significant investment in developing a shared educational environment. This investment will extend to collaborative practice experiences and serve as a model for the "health home."

To meet these objectives, it will also be necessary to recast traditional dental educational programs and consider developing alternative career paths that enable students to assume important leadership roles in public health, public policy, research, and community service. This emphasis on alternative career pathways, along with adoption of new knowledge domains and the reintegration of dental education with medicine, will produce dental graduates more capable of managing health in a more collaborative setting and ones who will be instrumental in leading this change. The continued artificial separation of dentistry from medicine and the lack of value placed on oral health have imposed significant costs on the health care system and society. Indeed, closer integration of oral and general health at the level of education, research, and patient care may well result in greater efficiencies, lower costs, and improved patient outcomes. ${ }^{77}$ 


\section{Global Oral Health}

As globalization of health care becomes a reality, dental schools need to provide dental students with a deeper understanding of the scope of untreated oral disease and lack of access to care in the developing world. ${ }^{78-81}$ Recently, the FDI World Dental Federation, World Health Organization (WHO), and International Association for Dental Research (IADR) outlined a series of goals for the year 2020 aimed at minimizing the impact of oral and craniofacial disease while promoting oral health in populations with the greatest burden of such conditions ${ }^{80}$ Another objective was to minimize the impact of oral and craniofacial manifestations of systemic disease in individuals and society and to focus more on early diagnosis and prevention to more effectively manage systemic disease. ${ }^{78}$

In the second edition of the Oral Health Atlas, epidemiological data revealed serious gaps in treating major oral diseases, particularly in low- and middleincome countries, and the overall awareness of oral diseases among policymakers was for the most part low. ${ }^{78}$ Existing interventions to prevent and control oral diseases were found to often be regarded as an expendable luxury, rather than a human right. In addition to the important advocacy roles dental schools play in support of efforts to improve the health of global communities, dental schools must play a leading role in educating students in global health policy issues. The profession can no longer ignore the global burden of oral disease that remains unattended to and continues to receive minimal resources for surveillance, prevention, care, and research. According to the FDI World Dental Federation, more than 4 billion people worldwide suffer from oral diseases, generating an enormous health and economic burden. It is only through continued research and training of future professionals to be leaders in global health that the necessary policy-based decisions will be crafted that will improve the health of patients in underserved communities.

It is imperative that dental schools promote, coordinate, and support the full range of basic, clinical, and translational research in global oral health if we hope to reduce the burden of disease in developing communities. The IADR Global Oral Health Inequalities Research Agenda identified research priorities designed to reduce oral health disparities worldwide. ${ }^{80}$ Dental schools should position themselves as integral to the global health care community in order to prepare graduates who believe it is their responsibility to reduce the burden of oral disease in the increasingly connected global community.

\section{Emerging Research Opportunities}

\section{Big Data Analytics}

The need to analyze and synthesize large data sets has been appreciated for many years. ${ }^{82-84}$ However, it has only been within the last decade that what is called "big data" has received muchneeded attention in the health care sector ${ }^{82,85-87} \mathrm{Big}$ data analytics have not only increased the speed and efficiency of retrieving information, but also made it possible to instantaneously reveal trends and novel insights. Securing, handling, and analyzing big data sets are fundamental to the advancement of the health care industry. It is also clear that assessing such data will provide a rich source for research to improve efficiencies in health care delivery and patient care. Patient records, health plans, insurance information, and other types of data can be difficult to manage, but are full of key insights once analytics are applied. By rapidly analyzing large amounts of information, health care providers can provide life-saving diagnoses or treatment options in near real time.

The rapid development of information technology and its integration into the health care industry have the potential to revolutionize the patient care environment and the education of health care providers. ${ }^{86-89}$ A good example of the application of analytics is the development of the learning health care system..$^{90-94}$ This interconnected system is informed by new evidence-based practice through clinical research, data analytics, modern information technology, and bioinformatics. As the personalized oral health care environment advances, it will become more complex, and providers will be increasingly judged by patients on their ability to rapidly adopt and implement best practices. When dentistry embraces a learning health care system, we can expect to realize an enhanced quality of oral health care, increased efficiencies, and better cost containment.

\section{Systems Biology}

Systems biology is a holistic approach to understanding the complexity of biological systems. It employs coordinated strategies that combine compu- 
tational and mathematical modeling to understand the complex networks that regulate cellular, organ, and systemic behavior. ${ }^{95-97}$ Systems biology is a pivotal feature of personalized medicine through its ability to analyze complex data and consolidate knowledge into definable networks. ${ }^{98}$ With the power of systems biology and the essential analysis of the big data sets it generates, it should be possible to leverage recent advances in technology to reveal biomarkers that will redefine disease diagnosis, etiology, and pathogenesis, patterns of disease risk, and new targeted therapies. Systems biology approaches have the potential to more rapidly implement more cost effective clinical trials and hasten the introduction of new therapies into the clinic. ${ }^{99,100}$ For complex diseases such as cancer, the genomic alterations, dysregulated metabolic pathways, and short-circuited signaling networks make it essentially impossible to identify a single reliable therapeutic target. A systems approach, however, enables a more rational method of integrating information, separating true disease drivers from noise, and identifying therapeutic candidates that can be manipulated..$^{99,101-103}$

\section{Tissue Engineering, Stem Cell Biology, Advanced Biomaterials}

Stem cell biology, advanced material design, and tissue engineering are examples of new scientific initiatives that will impact the future of health care. The objective of tissue engineering (TE) and stem cell biology (SCB) is to replace or regenerate damaged or congenitally missing tissues by combining undifferentiated or preprogrammed stem cells with highly porous scaffolds to guide the growth of new tissues. ${ }^{104-106}$ In addition, this strategy can serve as a delivery system for growth factors, adhesion molecules, and cytokines. ${ }^{42,105,107,108}$ This approach has wide application in a variety of settings in dentistry. ${ }^{106,109}$ In addition to replacing damaged or missing tissue or organs, the convergence of these fields will play an important role in developing a deeper understanding of tissue and organ regeneration and lead to innovative approaches to tissue and organ replacement. ${ }^{110-114}$ Finally, the use of scaffolds as delivery systems for therapeutic drugs or genes may provide a more stable and effective approach to allow sustained and controlled release of therapeutic agents. ${ }^{115}$

Among the most exciting areas in dental biomaterials is the application of nanotechnology to the detection, diagnosis, and treatment of disease. ${ }^{116-119}$
For example, silver base nanoparticles have been found to be effective against biofilms. ${ }^{120-122}$ Following binding to proteoglycans inside bacterial cells, the silver ions interact with sulfhydryl groups and interfere with DNA synthesis. ${ }^{17}$ Zinc, which has been used in dental cements, has anti-bacterial effects that are enhanced when present in nanoparticles. The antibacterial effect of zinc nanoparticles may be attributed to their interaction with the bacterial cell wall of several species and their ability to induce oxidative stress and generated reactive oxygen species. ${ }^{123-125}$ Other examples of antibacterial nanoparticles include titanium dioxide-based nanoparticles that cause oxidative death, copper-based nanoparticles that may alter protein synthesis although the precise mechanism of action is unclear, and quaternary ammonium nanoparticles that have promise as a delivery platform for selective controlled drug delivery. ${ }^{126-128}$ Lastly, quantum dots and nanocomposites have improved mechanical strength, color density, lower polymerization shrinkage, and overall improvement in adherence to dental tissues. ${ }^{117}$

Other emerging technology such as robotics, 3-D printing, advanced imaging, telemedicine, and remote care will no doubt find their way into dental practice. To make this a reality, however, all dental schools must make research, innovation, and collaboration an even larger part of the modern educational experience, and we should be working to lessen the role of the often-outdated textbook. With the extraordinary amounts of data available to us, it would be wiser to teach students the skills to find, critically analyze, and synthesize complex data rather than simply memorizing facts. It is only through an expanded interdisciplinary and transdisciplinary research effort that these seemingly impossible ideas can become the reality of tomorrow's health care norm.

\section{Conclusion}

The dental graduate of 2040 will face new and complex challenges. Chief among them will be the rapidly changing scientific landscape and the impact it will have on dental education and the practice environment. Several predicted outcomes and potential solutions are outlined in this article. From precision medicine to the learning health care system to global health care to the daily use of advanced technologies, all represent major challenges to our current dental education programs and practice environments. Despite all the warning signs indicating how the 
changing scientific and heath care landscape will dramatically affect dental education and the dental profession, there is little evidence that dental schools are reconsidering their research and educational priorities and clinical practice objectives. Until dental educators and the practicing community come to grips with these challenges, this persistent attitude of complacency will likely be at the dental profession's peril. We are at a tipping point in the oral health sciences, dental education, and dental practice. While we search for solutions to current and future challenges, economic uncertainty continues to limit research dollars that we desperately need to invest in our future. Dental education must continue to search for a new direction in a health care environment that is uncertain and unpredictable. If there was ever a time for courageous, innovative leadership, the time is now.

\section{Editor's Disclosure}

This article is published in an online-only supplement to the Journal of Dental Education as part of a special project that was conducted independently of the American Dental Education Association (ADEA). Manuscripts for this supplement were reviewed by the project's directors and the coordinators of the project's sections and were assessed for general content and formatting by the editorial staff. Any opinions expressed are those of the authors and do not necessarily represent the Journal of Dental Education or ADEA.

\section{REFERENCES}

1. Field MJ, ed. Dental education at the crossroads: challenges and change. An Institute of Medicine Report. Washington, DC: National Academy Press, 1995.

2. Lipton JA, Kinane DF. Total NIH support to U.S. dental schools, 2005-09. J Dent Res 2011;90(3):283-8.

3. Horvath Z, Albani SE, Wankiiri-Hale C. Training future dentists for an academic career: a three-tiered model. J Dent Educ 2016;80(5):502-16.

4. Roger JM, Wehmeyer MM, Milliner MS. Reflections on academic careers by current dental school faculty. J Dent Educ 2008;72(4):448-57.

5. Ferland CL, O'Hayre M, Knosp WM, et al. The NIH's funding to U.S. dental institutions from 2005 to 2014 . J Dent Res 2017;96(1):10-6.

6. Kornman KS, Duff GW. Personalized medicine: will dentistry ride the wave or watch from the beach? J Dent Res 2012;91(7 Suppl):8S-11S.

7. Kornman KS, Polverini PJ. Clinical application of genetics to guide prevention and treatment of oral diseases. Clin Genet 2014;86(1):44-9.

8. Garcia I, Kuska R, Somerman MJ. Expanding the foundation for personalized medicine: implications and challenges for dentistry. J Dent Res 2013;92(7 Suppl):3S-10S.
9. Guven Y, Uysal O. The importance of student research projects in dental education. Eur J Dent Educ 2011;15(2):90-7.

10. Emrick JJ, Gullard A. Integrating research into dental student training: a global necessity. J Dent Res 2013;92(12):1053-5.

11. Feinberg M, Garcia LT, Polverini PJ, et al. The vital role of research funding in preserving the oral health of the public and the dental profession. J Am Dent Assoc 2015;146(6):355-6.

12. Polverini PJ. Ensuring that research and discovery remain core values of dentistry. J Dent Res 2013;92(6):483-4.

13. Gies WJ. Dental education in the United States and Canada. New York: Carnegie Foundation for the Advancement of Teaching, 1926.

14. Kishore M, Panat SR, Aggarwal A, et al. Evidence-based dental care: integrating clinical expertise with systematic research. J Clin Diagn Res 2014;8(2):259-62.

15. Polverini PJ. A curriculum for the new dental practitioner: preparing dentists for a prospective oral health care environment. Am J Public Health 2012;102(2):e1-3.

16. Snyderman R, Yoediono Z. Prospective care: a personalized, preventative approach to medicine. Pharmacogen 2006;7(1):5-9.

17. Ginsburg GS, Willard HF. Genomic and personalized medicine: foundations and applications. Transl Res J Lab Clin Med 2009;154(6):277-87.

18. Commission on Dental Accreditation. Accreditation standards for dental education programs. Chicago: American Dental Association, 2016.

19. DePaola DP, Slavkin HC. Reforming dental health professions education: a white paper. J Dent Educ 2004;68(11):1139-50.

20. Nash DA. A path toward stagnation and the eventual decline of dental education and dentistry. Gen Dent 2014;62(5):9-10.

21. Flexner A. Medical education in the United States and Canada. New York: Carnegie Foundation for the Advancement of Teaching, 1910.

22. Dinan MA, Simmons LA, Snyderman R. Commentary: personalized health planning and the Patient Protection and Affordable Care Act, an opportunity for academic medicine to lead health care reform. Acad Med 2010;85(11):1665-8.

23. Hamburg MA, Collins FS. The path to personalized medicine. New Engl J Med 2010;363(4):301-4.

24. Snyderman R. Personalized health care: from theory to practice. Biotech J 2012;7(8):973-9.

25. Snyderman R, Dinan MA. Improving health by taking it personally. JAMA 2010;303(4):363-4.

26. Advancing oral health in America. An Institute of Medicine Report. Washington, DC: National Academies Press, 2011.

27. Crossing the quality chasm: a new health system for the 21 st century. An Institute of Medicine Report. Washington, DC: National Academy Press, 2001.

28. Greiner A, Knebel E. Health professions education: a bridge to quality. An Institute of Medicine Report. Washington, DC: National Academies Press, 2003.

29. Healthy people 2010: understanding and improving health. Washington, DC: U.S. Department of Health and Human Services, 2000. 
30. Improving access to oral health care for vulnerable and underserved populations. An Institute of Medicine Report. Washington, DC: National Academies Press, 2011.

31. Oral health in America: a report of the surgeon general. Rockville, MD: U.S. Department of Health and Human Services, National Institutes of Health, National Institute of Dental and Craniofacial Research, 2000.

32. Ahn AC, Tewari M, Poon CS, Phillips RS. The limits of reductionism in medicine: could systems biology offer an alternative? PLoS Med 2006;3(6):e208.

33. Godman B, Finlayson AE, Cheema PK, et al. Personalizing health care: feasibility and future implications. BMC Med 2013;11:179.

34. Manolio TA. Genomewide association studies and assessment of the risk of disease. New Engl J Med 2010;363(2):166-76.

35. Payne PR, Marsh CB. Towards a " $4 \mathrm{I}$ " approach to personalized health care. Clin Trans Med 2012;1(1):14.

36. Cohen JJ, Gabriel BA, Terrell C. The case for diversity in the health care workforce. Health Aff 2002;21(5): 90-102.

37. Mertz EA, Finocchio L. Improving oral health care delivery systems through workforce innovations: an introduction. J Public Health Dent 2010;70(Suppl 1):S1-5.

38. Gallagher JE, Wilson NH. The future dental workforce? Br Dent J 2009;206(4):195-9.

39. McKinnon M, Luke G, Bresch J, et al. Emerging allied dental workforce models: considerations for academic dental institutions. J Dent Educ 2007;71(11):1476-91.

40. Dounis G, Ditmyer MM, McClain MA, et al. Preparing the dental workforce for oral disease prevention in an aging population. J Dent Educ 2010;74(10):1086-94.

41. Syurina EV, Brankovic I, Probst-Hensch N, Brand A. Genome-based health literacy: a new challenge for public health genomics. Public Health Gen 2011;14(4-5): 201-10.

42. Baum BJ, Mooney DJ. The impact of tissue engineering on dentistry. J Am Dent Assoc 2000;131(3):309-18.

43. Rotroff DM, Motsinger-Reif AA. Embracing integrative multiomics approaches. Int J Gen 2016;1715985.

44. Chen R, Mias GI, Li-Pook-Than J, et al. Personal omics profiling reveals dynamic molecular and medical phenotypes. Cell 2012;148(6):1293-307.

45. Chen R, Snyder M. Promise of personalized omics to precision medicine. Wiley Interdisc Rev Syst Biol Med 2013;5(1):73-82.

46. Miller CS, Foley JD, Bailey AL, et al. Current developments in salivary diagnostics. Biomark Med 2010;4(1):171-89.

47. Tanaka H. Omics-based medicine and systems pathology: a new perspective for personalized and predictive medicine. Methods Inform Med 2010;49(2):173-85.

48. Wong DT. Salivary diagnostics powered by nanotechnologies, proteomics, and genomics. J Am Dent Assoc 2006;137(3):313-21.

49. Blue AV, Mitcham M, Smith T, et al. Changing the future of health professions: embedding interprofessional education within an academic health center. J Assoc Am Med Coll 2010;85(8):1290-5.

50. Crall JJ. Oral health policy development since the surgeon general's report on oral health. Acad Pediatr 2009;9(6):476-82.
51. Crosson FJ. 21st-century health care: the case for integrated delivery systems. New Engl J Med 2009;361(14): 1324-5.

52. Garcia RI, Inge RE, Niessen L, DePaola DP. Envisioning success: the future of the oral health care delivery system in the United States. J Public Health Dent 2010;70 (Suppl 1):S58-65.

53. Lavin MA, Ruebling I, Banks R, et al. Interdisciplinary health professional education: a historical review. Adv Health Sci Educ 2001;6(1):25-47.

54. Mitchell PH, Belza B, Schaad DC, et al. Working across the boundaries of health professions disciplines in education, research, and service: the University of Washington experience. J Assoc Am Med Coll 2006;81(10): 891-6.

55. Interprofessional Education Collaborative Expert Panel. Core competencies for interprofessional collaborative practice. Washington, DC: Interprofessional Education Collaborative, 2011.

56. Tedesco LA. Revising accreditation processes and standards to address current challenges in dental education. J Dent Educ 2008;72(2 Suppl):46-50.

57. Frenk J, Chen L, Bhutta ZA, et al. Health professionals for a new century: transforming education to strengthen health systems in an interdependent world. Lancet 2010;376(9756):1923-58.

58. Davies SM. Pharmacogenetics, pharmacogenomics, and personalized medicine: are we there yet? Hematology 2006;111-7.

59. Feero WG, Guttmacher AE, Collins FS. Genomic medicine: an updated primer. New Engl J Med 2010;362(21):2001-11.

60. Issa AM. Evaluating the value of genomic diagnostics: implications for clinical practice and public policy. Adv Health Econ Health Serv Res 2008;19:191-206.

61. Nibali L, Donos N, Henderson B. Periodontal infectogenomics. J Med Microbiol 2009;58(Pt 10):1269-74.

62. West M, Ginsburg GS, Huang AT, Nevins JR. Embracing the complexity of genomic data for personalized medicine. Genome Res 2006;16(5):559-66.

63. Eng G, Chen A, Vess T, Ginsburg GS. Genome technologies and personalized dental medicine. Oral Dis 2012;18(3):223-35.

64. Guttmacher AE, Porteous ME, McInerney JD. Educating health care professionals about genetics and genomics. Nature Rev Genetics 2007;8(2):151-7.

65. Haiech J, Kilhoffer MC. Personalized medicine and education: the challenge. Croat Med J 2012;53(4): 298-300.

66. Johnson L, Genco RJ, Damsky C, et al. Genetics and its implications for clinical dental practice and education: report of panel 3 of the Macy study. J Dent Educ 2008;72(2 Suppl):86-94.

67. Katsanis SH, Dungan JR, Gilliss CL, Ginsburg GA. Educating future providers of personalized medicine. North Carolina Med J 2013;74(6):491-2.

68. McInerney JD. Genetics education for health professionals: a context. J Genet Counsel 2008;17(2):145-51.

69. Salari K, Karczewski KJ, Hudgins L, Ormond KE. Evidence that personal genome testing enhances student learning in a course on genomics and personalized medicine. PloS One 2013;8(7):e68853. 
70. Skirton H, Lewis C, Kent A, Coviello DA, Members of Eurogentest U, Committee EE. Genetic education and the challenge of genomic medicine: development of core competencies to support preparation of health professionals in Europe. Eur J Hum Gen 2010;18(9):972-7.

71. Williams SD, Hughes TE, Adler CJ, et al. Epigenetics: a new frontier in dentistry. Austr Dent J 2014;59 (Suppl 1):23-33.

72. Clancy TE, Fiks AG, Gelfand JM, et al. A call for health policy education in the medical school curriculum. JAMA 1995;274(13):1084-5.

73. Patel MS, Davis MM, Lypson ML. Advancing medical education by teaching health policy. New Engl J Med 2011;364(8):695-7.

74. Patel MS, Lypson ML, Miller DD, Davis MM. A framework for evaluating student perceptions of health policy training in medical school. J Assoc Am Med Coll 2014;89(10):1375-9.

75. Boelen C. Commentary: a new paradigm for medical schools a century after Flexner's study. Bull WHO 2002;80(7):592-3.

76. DePaola DP. The revitalization of U.S. dental education. J Dent Educ 2008;72(2 Suppl):28-42.

77. Donoff B, McDonough JE, Riedy CA. Integrating oral and general health care. New Engl J Med 2014;371(24): 2247-9.

78. Jin LJ, Lamster IB, Greenspan JS, et al. Global burden of oral diseases: emerging concepts, management, and interplay with systemic health. Oral Dis 2015;22(7): 609-19.

79. Williams DM. Global oral health inequalities: the research agenda. J Dent Res 2011;90(5):549-51.

80. Sgan-Cohen HD, Evans RW, Whelton H, et al. IADR Global Oral Health Inequalities Research Agenda (IADRGOHIRA): a call to action. J Dent Res 2013;92(3):209-11.

81. Velji A. Education for global oral health: progress in improving awareness and defining competencies. J Dent Educ 2015;79(4):351-2.

82. Belle A, Thiagarajan R, Soroushmehr SM, et al. Big data analytics in health care. Biomed Res Int 2015;2015:370194.

83. Kudyba S. Big data, mining, and analytics components of strategic decision making. Boca Raton, FL: Taylor \& Francis, 2014

84. Lin N. Applied business analytics integrating business process, big data, and advanced analytics. Upper Saddle River, NJ: Pearson Education, 2014.

85. Costa FF. Big data in biomedicine. Drug Discov Today 2014;19(4):433-40.

86. Peters SG, Khan MA. Electronic health records: current and future use. J Comp Eff Res 2014;3(5):515-22.

87. Raghupathi W, Raghupathi V. Big data analytics in health care: promise and potential. Health Inform Sci Syst 2014;2:3.

88. Simpao AF, Ahumada LM, Galvez JA, Rehman MA. A review of analytics and clinical informatics in health care. J Med Syst 2014;38(4):45.

89. Viceconti M, Hunter P, Hose R. Big data, big knowledge: big data for personalized health care. J Biomed Health Inform 2015;19(4):1209-15.
90. Friedman C, Rubin J, Brown J, et al. Toward a science of learning systems: a research agenda for the highfunctioning learning health system. J Am Med Inform Assoc 2015;22(1):43-50.

91. Friedman CP, Wong AK, Blumenthal D. Achieving a nationwide learning health system. Sci Trans Med 2010;2(57):57cm29.

92. Grossmann C. Roundtable on value and science-driven health care: engineering a learning health care system-a look at the future, workshop summary. An Institute of Medicine Report. Washington, DC: National Academies Press, 2011.

93. Olsen L, Aisner D, McGinnis JM. Roundtable on evidence-based medicine: the learning health care system, workshop summary. An Institute of Medicine Report. Washington, DC: National Academies Press, 2007.

94. Roberts DW. Improving care and practice through learning health systems. Nurs Manag 2013;44(4):19-22.

95. Hood L. Systems biology and p4 medicine: past, present, and future. Rambam Maimon Med J 2013;4(2):e0012.

96. Hood L, Flores M. A personal view on systems medicine and the emergence of proactive $\mathrm{P} 4$ medicine: predictive, preventive, personalized, and participatory. New Biotech 2012;29(6):613-24.

97. Weston AD, Hood L. Systems biology, proteomics, and the future of health care: toward predictive, preventative, and personalized medicine. J Prot Res 200;3(2):179-96.

98. Chen R, Snyder M. Systems biology: personalized medicine for the future? Curr Opin Pharm 2012;12(5):623-8.

99. Matta A, Ralhan R. Overview of current and future biologically based targeted therapies in head and neck squamous cell carcinoma. Head Neck Oncol 2009;1:6.

100. Sookoian S, Pirola CJ. Liver enzymes, metabolomics, and genome-wide association studies: from systems biology to the personalized medicine. Wld J Gastro 2015;21(3):711-25.

101. Du W, Elemento O. Cancer systems biology: embracing complexity to develop better anticancer therapeutic strategies. Oncogene 2015;34(25):3215-25.

102. Gonzalez-Angulo AM, Hennessy BT, Mills GB. Future of personalized medicine in oncology: a systems biology approach. J Clin Oncol 2010;28(16):2777-83.

103. Tomita M, Kami K. Cancer: systems biology, metabolomics, and cancer metabolism. Science 2012;336(6084):990-1.

104. Xiao L, Nasu M. From regenerative dentistry to regenerative medicine: progress, challenges, and potential applications of oral stem cells. Stem Cells Cloning 2014; 7:89-99.

105. Abou Neel EA, Chrzanowski W, Salih VM, et al. Tissue engineering in dentistry. J Dent 2014;42(8):915-28.

106. Casagrande L, Cordeiro MM, Nor SA, Nor JE. Dental pulp stem cells in regenerative dentistry. Odontol Soc Nippon Dent Univ 2011;99(1):1-7.

107. Earthman JC, Sheets CG, Paquette JM, et al. Tissue engineering in dentistry. Clin Plast Surg 2003;30(4):621-39.

108. Galler KM, D’Souza RN. Tissue engineering approaches for regenerative dentistry. Regen Med 2011;6(1):111-24.

109. Chai WL. Tissue-engineering of oral mucosal equivalents in dentistry. Dent Update 2010;37(8):567; author reply 8 . 
110. Popovic N, Brundin P. Therapeutic potential of controlled drug delivery systems in neurodegenerative diseases. Int J Pharm 2006;314(2):120-6.

111. Joo S, Lim HJ, Jackson JD, et al. Myogenic-induced mesenchymal stem cells are capable of modulating the immune response by regulatory T cells. J Tissue Eng 2014;5:1-11.

112. Zhang X, Guo R, Xu J, et al. Poly(L-lactide)/halloysite nanotube electrospun mats as dual-drug delivery systems and their therapeutic efficacy in infected full-thickness burns. J Biomater Appl 2015;30(5):512-25.

113. Wang J, Wu W, Jiang X. Nanoscaled boron-containing delivery systems and therapeutic agents for cancer treatment. Nanomed 2015;10(7):1149-63.

114. Tahover E, Patil YP, Gabizon AA. Emerging delivery systems to reduce doxorubicin cardiotoxicity and improve therapeutic index: focus on liposomes. Anticancer Drugs 2015;26(3):241-58.

115. Raftery RM, Walsh DP, Castano IM, et al. Delivering nucleic-acid based nanomedicines on biomaterial scaffolds for orthopedic tissue repair: challenges, progress, and future perspectives. Adv Mater 2016;28(27): 5447-69.

116. Mitra SB, Wu D, Holmes BN. An application of nanotechnology in advanced dental materials. J Am Dent Ass 2003;134(10):1382-90.

117. Padovani GC, Feitosa VP, Sauro S, et al. Advances in dental materials through nanotechnology: facts, perspectives, and toxicological aspects. Trends Biotech 2015;33(11):621-36.

118. Mantri SS, Mantri SP. The nano era in dentistry. J Nat Sci Biol Med 2013;4(1):39-44.
119. Kanaparthy R, Kanaparthy A. The changing face of dentistry: nanotechnology. Int J Nanomed 2011;6:2799-804.

120. de Lima R, Seabra AB, Duran N. Silver nanoparticles: a brief review of cytotoxicity and genotoxicity of chemically and biogenically synthesized nanoparticles. J Appl Toxicol 2012;32(11):867-79.

121. Duran N, Marcato PD, Duran M, et al. Mechanistic aspects in the biogenic synthesis of extracellular metal nanoparticles by peptides, bacteria, fungi, and plants. Appl Micro Biotech 2011;90(5):1609-24.

122. Marcato PD, Duran N. New aspects of nanopharmaceutical delivery systems. J Nanosci Nanotech 2008;8(5):2216-29.

123. Hajipour MJ, Fromm KM, Ashkarran AA, et al. Antibacterial properties of nanoparticles. Trends Biotechnol 2012;30(10):499-511.

124. Huh AJ, Kwon YJ. "Nanoantibiotics": a new paradigm for treating infectious diseases using nanomaterials in the antibiotics resistant era. J Cont Release 2011;156(2): 128-45.

125. Huang Z, Zheng X, Yan D, et al. Toxicological effect of $\mathrm{ZnO}$ nanoparticles based on bacteria. Langmuir 2008;24(8):4140-4.

126. De Jong WH, Borm PJ. Drug delivery and nanoparticles:applications and hazards. Int J Nanomed 2008;3(2):133-49.

127. Byrne JD, Betancourt T, Brannon-Peppas L. Active targeting schemes for nanoparticle systems in cancer therapeutics. Adv Drug Deliv Rev 2008;60(15):1615-26.

128. Endo K, Ueno T, Kondo S, et al. Tumor-targeted chemotherapy with the nanopolymer-based drug NC6004 for oral squamous cell carcinoma. Cancer Sci 2013;104(3):369-74. 